\begin{abstract}
Three factors lead to the hypothesis that agenda-setting should be weaker at the local political level compared to the national level: (1) the more directly observable nature of local political problems, (2) the nature and strength of local interpersonal political communication networks, and (3) the relatively heavier media coverage of national political issues. This hypothesis was supported with data from respondents assigned at random to either local or national issue conditions and from a content analysis of television and newspaper coverage in Toledo, Ohio, of local and national issues. Contrary to the findings of certain previous studies, network television was found to exercise a stronger agenda-setting influence than newspapers at the national level. Newspapers, on the other hand, were the dominant agenda-setter at the local level. The relative agenda-setting intluences of television versus newspapers are consistent with other data from this study concerning the relative strengths of the various media as sources of issue information.
\end{abstract}

\title{
AGENDA-SETTING WITH LOCAL AND NATIONAL ISSUES
}

\author{
PHILIP PALMGREEN \\ University of Kentucky \\ PETER CLARKE \\ University of Michigan
}

An object of much recent research has been the identification of variables which mediate the agenda-setting function of the mass media. As McCombs (1976a: 2) states in his recent review of the agenda-setting literature, "No one contends that agenda-setting is an influence process operating at all times and all places in all people." In his review, McCombs identifies a number of "contingent conditions" which have been shown by research to affect agenda-setting. These include the individual's need for orientation, frequency of interpersonal discussion, level of media exposure, and voting decision state (decided versus undecided).

AUTHORS' NOTE: The research reported on here was supported by a Grant from the University of Michigan's Horace H. Rackham School of Graduate Studies.

COMMUNICATION RESEARCH, Vol. 4 No. 4, October 1977 (C)1977 Sage Publications, Inc. 


\section{THE EFFECTS OF POLITICAL SYSTEM LEVEL}

As this list illustrates, most of the mediating variables which have been identified thus far are at the psychological or individual level. Little attention, however, has been directed toward various systemic factors which might enhance, mitigate, or modify agenda-setting processes. Of particular relevance here might be the political system level (local-state-national) involved. Yet the great majority of agenda-setting studies have been concerned only with national issues, and then mostly within the limited context of political campaigns. Tipton, Haney, and Baseheart's (1975) investigation of the 1971 Kentucky gubernatorial campaign and Cohen's (1975) examination of the attributes of a local environmental issue in Indiana are among the few exceptions to this rule.

While each of these studies furnishes evidence of agenda-setting processes below the national level, there are numerous differences between the various political system levels, particularly between the local and national political spheres, which might lead us to expect similar differences in the ways in which individuals develop political cognitions about these areas. For example, the type and scope of local and national political issues differ widely. Many national political issues may be perceived by individuals to have little direct impact on their personal affairs. interest in national affairs is often dictated by an abstract empathic consideration for the welfare of the nation as a whole. A local plan for the busing of students, however, may inspire vigorous personal concern and participation in the political process. On the other hand, the grand scale of many national political issues imbues them with a perceived significance which cannot be matched by traditional local political fixtures such as street repair, even though the latter may possess immediate personal ramifications. For many persons, the magnetic attraction of politics on the grand scale may triumph over more immediate concerns about the quality of local garbage collection and lead to higher levels of information seeking about national affairs. 
Another important consideration is the relative "immediacy" of many issues at the local level. The ability of citizens to witness firsthand many local political problems and events often may obviate the need to rely on the mass media as "extensions of one's senses." Certainly a person does not need the media to inform him that street repair is a major community problem, particularly if one of the streets in question is in front of one's home. Neighborhood interpersonal networks are often heavily laden with content arising from personal observation. Since every citizen of the community is a potential initial source for such local political "news," it is easy to understand why this might be the case.

Further impetus is given to the importance of interpersonal channels vis-à-vis the mass media by the nature of organized group life in most communities. Many membes of local voluntary associations are at the same time elected or administrative officials in local government, or are important members of the local informal power structure (as businessmen, school administrators, lawyers, and so on). As such, these individuals are directly involved with many local political issues and are able to transmit their own local issue agendas to fellow group members who may be less politically active. Information about national political affairs is also transmitted in this fashion, but probably much less frequently.

Thus, both the ability personally to observe local problems and the greater influence of interpersonal channels at the local level should lead to a reduction in the influence of the media issue agenda on personal agendas.

Media Coverage Levels. One difference between the local and national political levels of obvious relevance to agenda-setting is the level of mass media coverage accorded issues of local or national origin. There is no doubt about mass media "gatekeepers" fascination with more momentous national issues. National affairs tend to receive the lion's share of coverage in most newspapers, with the possible exception of local weeklies. Television, with its national network ties, tends to lean even more 
heavily toward national political concerns. This national focus is in part dictated by economic considerations, of course. It is more economical to make heavy use of network or syndicated material (such as wire copy) than to invest heavily in local news operations.

The heavier flow of national political affairs information should have ramifications, of course, for media-related learning. In terms of sheer information availability and redundancy we would expect higher average levels of individual exposure to information about national political issues. This should result in higher levels of learning about national politics over a broader range of issues, problems, and personalities. Strictly in terms of issue salience, the greater magnitude of the media "stimulus" at the national level should lead to better learning of the media issue agenda than at the less heavily covered local political level.

Thus, three factors lead to the hypothesis that the agenda-setting influence of the mass media should be weaker with regard to local political issues: (1) the greater ability of individuals personally to observe local political problems, (2) the nature and strength of local interpersonal political communication networks, and (3) the relatively heavier media coverage of national political issues.

\section{NEWSPAPERS VERSUS TELEVISION}

\section{AS AGENDA SETTERS}

As McCombs (1976a: 3) has noted, "One of the especially intriguing questions arising from agenda-setting research is the relative efficacy of television and newspapers in influencing personal agendas." A number of studies (McCombs, Shaw, and Shaw, 1972; McCombs, 1976b; Tipton et al., 1975; McClure and Patterson, 1974a; Patterson and McClure, 1976; Mullins, 1973; Agnir, 1976; and Williams, 1975) have found the newspaper to be superior to television as an agenda setter.

Since once again the evidence here derives from the national political level (except for the Tipton et al. 1975 study of state issues), we might ask whether a similar 
superiority of newspapers would be observed with regard to local political issues. An examination of the characteristics of the two media in the local political context indicates that it would. If anything, we might expect to find an even greater superiority of newspapers. By almost any yardstick, only newspapers have a sufficient "newshole" remaining to give local issues substantial play once national issues have been allotted their customary heavy emphasis. Even supposedly "local" television news is often heavily infiltrated by national issues, especially in the late evening time slot.

Apparently reflecting this imbalance in the relative abilities of newspapers and television to cover the local scene, observers of local politics usually assign political preeminence to newspapers. Banfield and Wilson (1963: 313), without mentioning television, state flatly: "The metropolitan daily newspaper is one of the very few actors on the civic scene (the mayor or city manager is usually the only other) in a position both to take a comprehensive view of the public interest and to exercise a powerful influence upon all of the other actors. It is therefore a political institution of great importance." Long (1958: 260), in his classic essay on the local community as an "ecology of games," states that the local newspaper "has a great part in determining what most people will be talking about, what most people will think the facts are, and what most people will regard as the problems to be dealt with . . to a large extent, it sets the civic agenda."

Local political leaders evidently share such perceptions of important newspaper involvement in community affairs. In a survey of $\mathbf{4 5}$ city managers of U.S. cities with populations greater than 100,000 , Boynton and Wright (1970) found that over half of the managers estimated newspapers to be highly influential in determining the issues and policies of municipal government in their communities. In no community did a manager perceive newspapers to be without influence. By contrast, most managers saw television and radio as having only moderate or limited influence. 
In the present study, therefore, it was expected that newspapers would manifest a stronger agenda-setting effect (in terms of media agenda-public agenda correlations) than would television with both local and national issues, but that the relative dominance of newspapers would be greater at the local level.

\section{PROBLEMS IN MAKING LOCAL VERSUS NATIONAL COMPARISONS}

Although a comparison of agenda-setting processes across political system levels would certainly appear desirable, such comparisons are not easily made. Simply comparing studies which employ national issues with others focusing on local issues can be highly misleading, since any differences observed may be due to differences in samples of respondents, media systems, and operationalization of variables. In particular, agenda-setting studies are likely to employ different content analysis procedures, issue classification systems, analytical schemes, and methods of measuring the public issue agenda (e.g., interpersonal versus intrapersonal). Thus, the Cohen (1975) study, the only previous study of agenda-setting which employed local issues, cannot be juxtaposed with the myriad national investigations to provide direct local versus national comparisons.

The present study attempted to remedy these and similar comparison problems by randomly assigning respondents in the same city (Toledo, Ohio) to either local or national issue "conditions," and by employing the same measurement and analytical procedures in both samples.

\section{METHODOLOGY}

Data were gathered in Toledo over a three-day period in early December 1973 as part of a broad study of political communication and information holding. The selection of Toledo was based on two major criteria. First, its status as a major metropolitan area (population 379,104 in 1970) assured it of a large number of local issues or problems in the political arena at any particular point in time. Second, Toledo 
has a well-developed mass media system for covering both local and national political issues.

Personal interviews were obtained via professional interviewers from a modified random sample (sex and age quotas were imposed) of 400 residents of the city of Toledo (18 years of age and older). Every other household within randomly selected block clusters was alternately assigned either the local or national version of the questionnaire. This resulted (after removal of certain unusable questionnaires) in local $(n=189)$ and national $(n=184)$ samples which were closely matched on a range of demographic and communication variables such as age, sex, race, length of residence, voter registration, and newspaper and television use. In addition, the demographic characteristics of both samples conformed closely to 1970 IJ.S. Census figures.

Measuring the Public Agenda. Respondents were asked to name "any problems facing people in this country [or Toledo, depending upon whether the respondent was assigned to either the local or national condition] which you think the government in Washington [Toledo city government] should work to help solve." The respondent was then asked to choose that problem which he considered to be "most important." The interview proceeded to focus on this problem.

Measuring the Media Agenda. A content analysis of Toledo newspaper and television coverage of nominated problems was carried out for the two weeks immediately prior to the gathering of interviews. A comprehensive listing first was made of all issues nominated by respondents at both political levels. After some collapsing into categories, this resulted in a total of 55 issues nominated at the local level and 33 at the national. Certain issues were nominated at both the local and national levels (e.g., "energy crisis," "crime"), resulting in a total of 73 separate issues nominated. Content analysis category descriptions were devised for each of these issues. In most cases where an issue was nominated at both local and national levels (e.g.. "crime," "energy crisis"), both Toledo and non-Toledo (state, na- 
tional) media content was included in arriving at the media coverage level for that issue. For example, all stories about crime, whether they concerned crime in Toledo or crime in other areas of the United States, were included in calculating the total media coverage level for "crime." This coverage level was then assigned to respondents in both the local and national political focus samples. An exception to this policy was made in those cases where the respondent specifically focused on either a local or national aspect of an issue (e.g., "education," where most local respondents were concerned specifically with improving the Toledo school system). In such cases, only local Toledo content was employed in the coverage index for local respondents, while both Toledo and non-Toledo content was used in the index for national respondents.

Newspaper coverage was indexed by enumerating the total number of "stories"1 relating to each issue category (some stories related to more than one issue) which appeared in the Toledo Blade for the period November 19-30, 1973. Coverage indices for the three major television networks for the same period were based on an analysis of summaries of the evening news contained in Television News Index and Abstracts, published by the Vanderbilt Television News Archives of Vanderbilt University. ${ }^{2}$ Since the evening news was broadcast during this period in the same time slot by all three networks, an average television coverage index was calculated. Local television news coverage was based on an analysis of transcripts of the 6:00 p.m. and 11:00 p.m. newscasts of the three major Toledo television stations. Again, an average index was calculated. ${ }^{3}$ An index of total mass media coverage was arrived at by summing the indices for the Blade, the national networks, and the local stations. ${ }^{4}$

\section{RESULTS}

There are rather striking differences in the number and kinds of issues which people singled out for attention at the 
local and national levels of government. At the national level, only 33 issues were mentioned, with the energy crisis (62 mentions) and corruption in government (45 mentions) dominating the agenda. The only other issues receiving significant attention were inflation (18 mentions) and welfare-poverty (13 mentions).

This high level of consensus is somewhat less in evidence at the local level. There, 55 different issues were nominated, headed by crime (39 mentions), housing (16) welfarepoverty (12), the local educational system (10), and urban renewal (9). Local aspects of the energy crisis also received some attention ( 9 mentions). Although several other issues received such dual mention at both the local and national levels (e.g., crime, unemployment, drugs), the agenda on the. whole are characterized by very dissimilar kinds of issues, reflecting, it would appear, a rather acute public awareness of the differing scope and functions of local and national government.

Table 1 provides a medium-by-medium comparison of issue coverage levels. The greater "newshole" available to newspapers is apparent at the local and national levels. Overall, issues most frequently nominated by national respondents received dramatically heavier mass media coverage than local issues. National issues received twice as much coverage on the average $\left(\bar{X}_{N}=34.7\right.$ stories) than did local issues $\left(\bar{X}_{L}=17.1\right)$. When each issue is weighted by the number of respondents nominating that issue, the average coverage level is $\mathbf{1 5 2 . 3}$ stories for national respondents and 61.6 for local respondents. Of national respondents, $58 \%$ nominated issues which received attention in at least 187 newspaper and television stories in the two weeks prior to interviewing. By comparison, $57 \%$ of local respondents nominated issues receiving coverage levels of only 16 stories or less.

The energy crisis, perceived chiefly as a national level issue, received the greatest share of media coverage $(273$ stories). Continued fascination with the Watergate scandal 
TABLE 1

Coverage (number of stories) by Medium of Local and National lssues

\begin{tabular}{|c|c|c|c|}
\hline & & MEDIUM & \\
\hline $\begin{array}{l}\text { ISSUE } \\
\text { IEVER }\end{array}$ & Newspapers & $\begin{array}{l}\text { Local } \\
\text { Television }\end{array}$ & $\begin{array}{c}\text { Rational Network } \\
\text { Televiglon }\end{array}$ \\
\hline $\begin{array}{l}\text { Local } \\
\text { (55 tasues) }\end{array}$ & $\begin{array}{l}606 \\
(347)^{* *}\end{array}$ & $\begin{array}{l}210 \\
(113)^{\circ}\end{array}$ & $\begin{array}{c}125 \\
(18)\end{array}$ \\
\hline $\begin{array}{l}\text { Kational } \\
\text { (33 issues) }\end{array}$ & $\begin{array}{c}745 \\
(596)\end{array}$ & $\frac{244}{(211)^{\prime}}$ & $\begin{array}{l}157 \\
(152)\end{array}$ \\
\hline
\end{tabular}

6:00 p.m. and 11:00 p.m. coverages are summed in this index. See note 3.

"Coverage levels with stories concerned with "corruption in government" and the "energy crisis" (issues perceived chiefly as national issues) removed.

"* Coverage levels with stories concerned with "crime" (an issue perceived chiefly as a local issue) removed.

accounted for the great majority of the 190 stories related to "corruption in government." Apparently reflecting this overwhelming media emphasis, these two issues were nominated as "most important" by 107 of the 184 national respondents. By contrast, these issues received only 10 nominations at the local level. At the local level, only the ubiquitous issue of crime (187 stories, 39 nominations) commanded coverage or nomination levels approaching those of the dominant national issues (except for local aspects of the energy crisis).

Agenda-Setting. These findings thus are consistent with the generally recognized tendency of the media to give greater play to national issues. It was hypothesized that this tendency, in conjunction with the directly observable character of many local jolitical problems and the nature of local interpersonal political networks, would result in a weaker media agenda-setting influence at the local issue level. This hypothesis received strong support in this study, as evidenced by the respective local and national correlations between total media coverage levels for each issue and the 
TABLE 2

Correlations (Pearson r) Between Issue Coverage and Salience of Issues-by News Medium and by Local and National Levels

\begin{tabular}{|c|c|c|c|}
\hline \multirow[b]{2}{*}{$\begin{array}{l}\text { ISSUE } \\
\text { LEVVEL }\end{array}$} & \multicolumn{3}{|c|}{ MEDIUM } \\
\hline & Newspapers & $\begin{array}{c}\text { Local } \\
\text { Television }\end{array}$ & $\begin{array}{c}\text { National lletwork } \\
\text { relevision }\end{array}$ \\
\hline Local & $.65^{*}$ & $.50^{\circ}$ & .13 \\
\hline Nat1onal & $.70^{*}$ & $.85^{\circ}$ & $.92^{\circ}$ \\
\hline
\end{tabular}

$\cdot p<.001$.

proportion of respondents at each political level who nominated each issue as "most important." The correlation (Pearson $r$ ) at the local level is a modest .53 ( $n=55$ issues), while at the national level ( $n=33$ issues) it is a relatively strong .82 (difference between r's significant at .01).

Newspapers versus Television. It was hypothesized that when agenda-setting is broken down by individual medium, the newspaper would prove to be a stronger agenda-setter than television, and that this superiority would be even stronger with regard to local issues. This hypothesis received only partial support, and, as the data in Table 2 reveal, there is a need to specify which type of television coverage is under consideration, since large differences emerge in the relative influence of local television news and national network coverage. ${ }^{5}$

As expected, newspapers (the Blade) exerted the strongest influence on respondents' local issue priorities, followed by local television news. As one would expect, national network television coverage had no significant impact on local public issue salience.

At the national level, however, national network television is clearly superior to the Blade in setting the public agenda. The strong correlation (.92) between network news coverage and the public hierarchy of issue salience 
is all the more impressive in view of the large number of issue categories (33) on which the correlation is based (since inflation due to issue aggregation is minimized). In any case, the results clearly are not in line with those of previous studies indicating a superiority of newspapers over television in setting national issue agendas. This discrepancy is further underlined by the strong agendasetting influence of local television news $(r=.85)$. This latter influence may be traced to the liberal coverage of issues defined as "national" (by respondents) provided by the Toledo stations in their "local" news telecasts.

A major reason for the discrepancy between this and prior studies may be that previous studies have been conducted during national campaigns, while this investigation took place in a noncampaign setting. McClure and Patterson's (1974b: 24-25) study of the 1972 presidential campaign indicated that "if coverage of events like the Watergate incident and the peace talks is eliminated, [national] television news gave more coverage to campaign activity-rallies, polls, strategies-than to issues." Fully one-third of the campaign coverage was devoted to such stories. Thus, in the supposedly issue-oriented atmosphere of a campaign, extensive television coverage of these issues paradoxically was lacking. During noncampaign periods, however, in the absence of the magnetic attraction of campaign hoopla, broadcast journalists appear to devote more attention to the substantive issues of the day. This seems to be particularly true of the time period spanned by the content analysis phase of this study. Both the energy crisis and Watergate, the two issues most frequently nominated by national respondents, received heavy amounts of network (and "local" TV) coverage during this period. It appears reasonable to hypothesize that during periods when television coverage of issues is relatively lacking (e.g., during campaigns), the agendasetting influence of this news source will be correspondingly diminished. When the magnitude of the issue "stim- 
TABLE 3

Percentages of Respondents Naming

Each Medium as Carrying the Most Information about lssues

\begin{tabular}{|c|c|c|c|c|}
\hline \multirow{2}{*}{$\begin{array}{l}\text { ISSUE } \\
\text { LEVEL }\end{array}$} & \multicolumn{3}{|c|}{ YEDIU: } & \multirow[b]{2}{*}{ Radto } \\
\hline & Newspapers & Television & Magazines & \\
\hline Local" & 45.48 & 45.48 & 3.10 & 6.19 \\
\hline Mational " & 32.64 & 52.28 & 21.68 & 3.68 \\
\hline
\end{tabular}

-Local $n=130$, national $n=138$. Fitty-one local and 43 national respondents felt no mass medium offered useful information.

ulus" is relatively strong, the agenda-setting impact of television will be proportionately greater. 6 Newspapers, on the other hand, with much greater "newshole" and thus much greater flexibility in their ability to cover both issues and non-issue related events simultaneously, should show greater stability in agenda-setting influence over time.

The Media as Sources of Issue Information. The relative agenda-setting influence of television versus newspapers found in this study are consistent with other data concerning the relative strengths of the various media as sources of issue information at the local and national issue levels. Table 3 shows the percentages of respondents naming each of four media as carrying "the most information that is useful" concerning each respondent's self-nominated "most important issue." At the national level, $52.2 \%$ of those naming such a medium said television (no distinction was made between network and local TV) carried the most useful information. Newspapers were far behind, with only $32.6 \%$. At the local level, newspapers and television shared the leadership position, with both preferred by $45.4 \%$ of the local respondents. It may be assumed that respondents here meant local 
[448] COMMUNICATION RESEARCH / OCTOBER 1977

TABLE 4

Percentages* of Respondents Discriminating One or More Messages From Each Medium

\begin{tabular}{|c|c|c|c|c|}
\hline \multirow[b]{2}{*}{$\begin{array}{l}\text { ISSUE } \\
\text { IEVVEL } \\
\end{array}$} & \multicolumn{3}{|c|}{ ERTrus } & \multirow[b]{2}{*}{ Readio } \\
\hline & Newsoapers & Television & Magazines & \\
\hline Local & 31.71 & 23.88 & 0.58 & 5.89 \\
\hline National & 42.18 & 51.91 & 7.38 & 11.58 \\
\hline
\end{tabular}

- Percentages do not total to $100 \%$ since respondents could cite more than one source for each recalled message.

TV news coverage, which displayed local agenda-setting power close to that of newspapers.

Of perhaps a more valid nature are data (see Table 4) indicating the number of respondents who could actually recall having "seen, read, or heard" anything concerning their "most important" issues in the Toledo media in the two weeks prior to the interview. These message discrimination data show television (again, no distinction between network and local TV) once again as the primary source of information about national issues, with $51.9 \%$ of respondents able to recall at least one message from that medium.? Newspapers are second with $42.1 \%$. On the other hand, newspapers provided the most information about local issues $-31.7 \%$ discriminated messages from that source compared to $23.8 \%$ for television.

It should be noted that message discrimination measures are indices of "effective" issue coverage by the various media, once audience members' information selection processes have had an opportunity to operate. The presence of issue information in media channels cannot induce agenda-serting effects unless audience members are exposed to that information. The concept of "effective coverage" is particularly important with regard to the relative impact of newspapers and television at the national 
level. On the basis of sheer coverage levels, we would expect newspapers to be the dominant agenda-setter at the national level (see Table 1). Apparently, however. television is more "efficient" in disseminating its messages, as the data in Tables 3 and 4 indicate. This greater efficiency is translated into the relatively stronger agendasetting effect of television for national issues.

\section{DISCUSSION}

The results of this study indicate, then, that the media play very different agenda-setting roles depending on whether the issues under study are of local or national political origin. First, the agenda-setting impact of the media as a whole vis-à-vis other information sources is generally weaker at the local level. Squaring the agendasetting correlations found at each political level reveals that the media agenda (all media combined) accounted for a sizable $67 \%$ of the variance in the public agenda at the national level, while "explaining" only $28 \%$ of the variation in local issue salience. While the latter percentage still is indicative of considerable media influence at the local level, the impact of alternative sources of information (e.g., interpersonal channels, personal observation) is strongly indicated.

Second, the relative agenda-setting influence of newspapers and television appears to depend on the political level involved. Newspapers, network television, and local television news programs have very different informational roles to play at each level. These differences are reflected in agenda-setting terms.

The results here also strongly suggest the need to consider still another political context variable in making intermedia comparisions: campaign versus noncampaign periods. It seems highly plausible that the discrepancy between the findings of this study and earlier inquiries into the relative agenda-setting powers of newspapers and television is due to the noncampaign context of this investigation. Comparative studies which employ the same 
methodology in exploring agenda-setting during campaign and noncampaign periods are needed.

As McCombs (1976a: 4) has observed, "Public issues can be arrayed along numerous dimensions: local versus national, the personally-close versus the distant, emotional vs. abstract, etc. It is not likely that the agenda-setting function of the mass media is concerned equaliy with all types of issues ceteris paribus. The salience of some types of issues on personal agenda are likely to show significant media influence while others show little or no such influence. Furthermore, interactions between types of issues and other agenda-setting variables are highly likely." The wisdom of these observations is amply demonstrated by the findings of this study. Certainly the agenda-setting function, which emerged initially in a form hauntingly reminiscent of the old "hypodermic needle" model of media effects, has been shown by recent research to be a highly complex phenomenon contingent on a variety of conditions. Type of issue would seem to be one condition deserving special research attention.

\section{NOTES}

1. For newspapers, a "story" was defined as any general news item, analysis piece, feature article, or editorial occupying three or more column inches (photographs and editorial cartoons were excluded). For multiple-topic items, the item was coded in a particular category only where at least one column inch (total) of copy was devoted to the topic. For both newspapers and television, an item was coded in as many categories as applied. Also, only content was coded which directly concerned events in the United States, except where the topic was international in focus (e.g., "underfed children overseas"). Items which for the most part concerned non-Toledo affairs, but which specifically related the topic in question to Toledo, were coded under both non-Toledo and Toledo content categories.

2. In the process of abstracting, the Television News Archive classifies the content of each news program into separate "stories." Each of these stories is presented in the abstracts as a separate paragraph. These paragraphs were thus used as the story unit for content analysis purposes.

3. The local television news transcripts also preclassified different news stories by presenting each story in a separate paragraph. Six $0^{\circ}$ clock and 11:00 p.m. coverages were summed to reflect the greater probability of audience exposure to content carried in both time slots. 
4. An intercoder reliability check was carried out for the coding of the Toledo Blade. This check revealed $84.2 \%$ agreement in coding a sample of items into the various content categories. A similar check on the coding of the television network news summaries and local television news transcripts was not considered necessary, since the newspaper content was judged to be the most difficult to code and thus most subject to coding error.

5. Zero-order instead of partial correlation coefficients were employed because the high intermedium coverage correlations at both the local and national levels (r's ranged from .75 to .92) would have caused severe multicollinearity problems. The estimates of the partials thus would have been highly unstable (see Blalock, 1963; Farrar and Glauber, 1967).

6. McClure and Patterson (1974b) state that television network news must meet five preconditions if it is to have "a unique and powerful impact." One of these conditions is that the event must take place outside the context of a political campaign.

7. For in-depth discussions of the message discrimination technique see Clarke and Kline (1974), Palmgreen, Kline, and Clarke (1974), and Miller (1974).

\section{REFERENCES}

AGNIR, F. (1976) "Testing new approaches to agenda-setting: a reflection and extension," in M. McCombs and G. Stone (eds.) Studies in Agenda Setting. New York: Syracuse University Newhouse Communications Research Center.

BANFIELD, E. C. and J. Q. WILSON (1963) City Politics. Cambridge, MA: Harvard University Press.

BLALOCK, H. M. (1963) "Correlated independent variables: the problem of multicollinearity." Social Forces 42: 233-237.

BOYNTON, R. P. and D. S. WRIGHT (1970) "The media, the masses, and urban management." Journalism Q. 47: 12-19.

CLARKE, P. and F. G. KLINE (1974) "Media effects reconsidered: some new strategies for communication research." Communication Research 1: 224-240.

COHEN, D. (1975) "A report on a non-election agenda-setting study." Paper presented to the Association for Education in Journalism, Ottawa, Canada.

FARRAR, D. E. and R. R. GLAUBER (1967) "Multicollinearity in regression analysis: the problem revisited." Rev. of Economics and Statistics 49: 92-107.

LONG, N. E. (1958) "the local community as an ecology of games." Amer. J. of Sociology 64: 251-261.

McCOMBS, M. (1976a) "Agenda-setting research: a bibliographic essay." Pol. Communication Rev. 1: 1-7.

- (1976b) "Mass communication effects across time," in D. L. Shaw and M. McCombs (eds.) The Emergence of Public Issues. (in press)

. D. SHAW, and E. SHAW (1972) "The news and public reponse. Three studies of the agenda-setting power of the press." Paper presented to the Association for Education in Journalism, Carbondale, Illinois.

McCLURE, R. D. and T. E. PATTERSON (1974a) "Agenda-setting: comparison of newspaper and television network news." Paper presented to the Conference on the Agenda-setting Function of Mass Communications. Syracuse University. New York. 
(1974b) "Television news and political advertising: the impact of exposure on voter beliefs." Communication Research 1: 3-31.

MILLER, P. V. (1974) "Issues in conceptualization and measurement of message discrimination." University n! Michigan Program for Mass Communication Research. (unpublished)

MULLINS, L. E. (1973) "Agenda-setting on the campus: the mass media and learning of issue importance in the "72 election." Paper presented to the Association for Education in Journalism, Fort Collins, Colorado.

PALMGREEN, P., F. G. KLINE, and P. CLARKE (1974) "Message discrimination and information holding about political affairs: a comparison of local and national issues." Paper presented to the International Communication Association, New Orleans.

PATTERSON, T. E. and R. D. MCCLURE (1976) The Unseeing Eye. New York: G. P. Putnam.

TIPTON, L. P., R. D. HANEY, and J. R. BASEHEART (1975) "Media agenda-setting in city and state election campaigns." journalism $Q$. 52: 15-22.

WILLIAMS, W. (1975) "The agenda-setting function of newspapers and public radio: an analysis of the intrapersonal method." Paper presented to the Speech Communication Association, Houston, Texas.

Philip Palmgreen is an Assistant Professor in the Department of Human Communication at the University of Kentucky. His research interests ore in political communication. communication theory. and media effects.

Peter Clarke is Professor and Chairman of Journalism. University of Michigan. His research interests include communication and political behavior, as well as use of mass media by the young, and he is co-Series Editor (with F. Gerald Kline) of Sage Annual Reviews of Communication Research. 